\title{
LA INTERVENCIÓN PEDAGÓGICA COMO FACTOR DE EQUILIBRAMIENTO DE LA PERSONALIDAD DEL DOCENTE
}

\author{
JOAQUÍN GARCÍA CARRASCO \\ Universidad de Salamanca
}

Si al despacho de un psicólogo o psiquiátra llega un físico que se siente desgraciado, no es recomendable iniciar el estudio empírico de su padecimiento psíquico analizando el estado actual de la física nuclear, ni tiene por qué recluirse el terapéuta en la biblioteca de algún instituto tecnológico, antes de formular el diagnóstico o iniciar la terapia.

En el caso de la Pedagogía - por las particulares situaciones epistemológicas y socioculturales del discurso educacional - un indicio más a tener en cuenta en la explicación final de los derroteros por lo que un maestro, un profesor, llegó a sentirse infeliz en su oficio es, sin duda alguna, el análisis de las percepciones sociales acerca de la actividad docente; el estudio de las proyecciones motivacionales y finalísticas, que se adjudican al quehacer de enseñar; las percepciones sociométricas del propio profesor, sobre la forma en que es percibida o descrita su función y el modo de asumirlas, el modo y manera cómo se llaga a ejercer de profesor...

Con ello, no queremos entrar en el debate técnico sobre el origen fundamental de la neurosis o de los comportamientos neurotizoides. Queremos poner de relieve que, dada la configuración sociocultural de la profesión docente -en la que no quedan solamente implicadas destrezas técnicas, sino autoconceptos y representaciones sociales y culturales pertenecientes al mercado de símbolos-, estudiar el discurso sobre la intervención pedagógica descubre que la mejora y el equilibramiento personal quedan afectados por la reestructuración de las representaciones conceptuales desde la que se interpreta personal y socialmente la intervención pedagógica. La acción seguirá también aquí al pensamiento, consciente o inconscientemente.

Mi reflexión, aquí y ahora, consistirá, pues, en advertir que el campo representacional que soporta la acción pedagogica está, para muchos docentes, muy desestructurado. La interpretación particularizada de las situaciones educativas puede dirigir la "proacción" (Murray) de la personalidad en el sentido de transformar, tales situaciones docentes, en especialmente 
amenazantes. Es la simiente de una esquizoidía intelectual entre lo que selectivamente inscribirá el profesor como vivir, y la ocupación profesional en que se siente como desviviendo.

La seguridad que se adquiere cuando se precisan los límites reales de la acción pedagógica, y el aumento de la percepción científica de los procesos en ella implicados, creemos que adquiere un significado preventivo de molestias psicológicas para los docentes; molestias que alimentan el modo y contenido de la representación simbólica de la propia actividad. Factor éste que entra, como elemento cognitivo, a formar parte de las actitudes personales ante y dentro del ejercicio profesional.

Las representaciones que vamos a estudiar no las estraemos de los libros pedagógicos especializados, sino de esos ámbitos literarios en los que se vierten productos mentales activos, condensaciones de las estimaciones sociales: el ámbito propio del pensamiento no construido con el método científico. Lo hacemos así, por estimar que, para muchos profesores, tales insinuaciones configuran niveles de riesgo. La seguridad en la acción, y un conocimiento rico en el que obtenerla, puede, en ocasiones, adquirir funcion preventiva. El conocimiento objetivo aumenta el realismo de la visión, la disminución de los fantasmas, el equilibramiento de la personalidad. Hay elementos en el ambiente que no son precisamente tranquilizadores, o por exceso o por defecto. Demos algunos indicios.

\section{LA MITIFICACIÓN DE LA FUNCIÓN PEDAGÓGICA}

Al menos en los hábitos culturales euopeos hay una propensión a mitificar la función pedagógica.

a) Los mitos bellos

Andan por ahí mitos hermosos sobre la actividad docente. Tchinghiz Aitmatov, en su novela corta "El primer maestro" (1976), pinta un personaje muy atractivo, quien adquirió su formación en el ejército - no en la Escuela de Formación de profesores- movido por el afán simple de conocer. Ocupará en las aldeas el lugar de los "mollah", sacerdotes musulmanes. Aparentemente, tendrá que luchar contra el desconocimiento y el analfabetismo, sin fuentes convencionales de ingresos; aparece como una situeta solitaria que adecenta con arcilla un corral hasta convertirlo en Escuela.

Este personaje desconocido, políticamente irrelevante pide a los niños (sin acreditar sus títulos) que le llamen maestro. El maestro reconforta a los pequeños con palabras afables y encuentra los caminos para que nazca 
en los alumnos el orgullo de estudiar. En su contra se encuentra el grupo que maneja el instrumento absorvente con que se consigue la comida (la azada), el condjunto de los tutores y guardianes de los niños que los crían y los desconocen, y los mismos niños que andan como cabos sueltos oponiendo resistencia a quien tira de ellos hacia los ideales de la comunidad. Parece que el maestro y sus ideales se enfentan al mundo. Asemeja a un hombre que hubiese adquirido no se sabe dónde ni de quien -quizás del interior de su propia conciencia- la responsabilidad sobre el hombre. Así de metafísico.

La voluntad del maestro descrita en el relato es la de vaciarse, la de enseñar todo lo que sabe y ayudar a ir por el camino que conoce: cree que el conocimiento para ser tal, ha de adquirir un carácter público y dejar de ser propiedad privada, pasar de un hombre a otro, porque la verdad adquiere nuevas calidades al comunicarse. A este maestro le mueve una pasión interior, ayuda sin programa y sin método de enseñanza, por intuición. Establece vínculos intimos con los alumnos y permanece incomprendido por el hombre convencional, para quien este maestro no pasa de ser "un chiflado que se entretiene con los chicos a falta de mejor ocupación".

Los niños, en cambio, aman a su maestro. Duishén - que así se llama-" por su sensibilidad, por sus pensamientos llenos de bondad, por su fe en el porvenir". Hasta los rasgos fisonómicos, que le describen en la novela, acompañan el cuadro tan apostólico - ya se dijo que la cara es el espejo del alma-: sus cejas forman una línea "como las alas desplegadas del águila. Su rostro parecía forjado en hierro". En el mito, el maestro trabaja contra un cuadro de barbarie y unos tiempos de atropello. El maestro aparece como quien condensa todos los proyectos que, pegando alarido se escapan de la historia. El niño nace con duros propietarios - padres, nivel social, tradiciones, modos hábitos...- y los maestros, con su intervención, los convierten en libres ciudadanos del mundo. De todo ello es símbolo la escuela y de todo ello es agente el maestro del mito.

En el relato, por supuesto, se compone un mundo imaginario. Pero no cualquier mundo de imaginación, sino aquél que transfiere a tiempos pretéritos el deber ser que habría de cumplirse en cada profesor, en cada espacio pedagógico, en cada oportunidad que la Sociedad da seriamente un paso hacia ese punto fácil del discurso que describe los confines de los deseos colectivos. En los libros se habla de fines educativos; en rigor, son límites y perfiles finales de descripciones utópicas. Aunque el novelista describe ficciones, muchos maestros les encontrarán parecidos con acontecimientos en los que ellos mismos fueron protagonistas. Casi todos los hombres, al describir la función educadora, emplean como tela la pared de fondo de una escuela; $y$, como dibujo, perfiles y siluetas de aspiraciones insatisfechas.

Se torna y convierte el maestro en foco de una equivocación y despiste: 
las transformaciones históricas o la dinámica integral del comportamiento se ven fruto de un proyecto de acción exclusivamente individual, un problema de intenciones. Ese proyecto contiene algunos supuestos, entre ellos el de que el hombre se talla y se pule a golpe severo de experto, en el espacio que crea un esquema de relaciones hombre-hombre. El profesor, tal vez sea el profesional sobre el que recae más férreamente la coerción sociocultural. En los mitos, en el lenguaje protocientífico, en el lenguaje coloquial, se le pide demasiado.

$\mathrm{Y}$, si el mismo alimenta su actividad con el producto exclusivo, creemos que se ha creado una zona de riesgo para el equilibrio de su propia personalidad.

Dos grandes movimientos culturales de la humanidad entre otros, y que reflejan dos grandes perspectivas sobre la totalidad real -en el sentido que da al término Ortega y Gasset puesta en razón- contuvieron, en sus referencias sobre el hombre, mitos educacionales.

La cultura griega en su momento de inicial explendor propuso, por boca de Sócrates en el Menon platónico el mito de la reminiscencia. El saber humano y los motivos y motores ideales de su acción se contienen seminalmente en todo hombre, como reminiscenia y huella de la eterna experiencia de su espíritu en el eterno pretérito. El maestro, que con el auxilio del arte mayéutico actúa de partero, demuestra en el experimento con el esclavo que en todo hombre es posible todo conocimiento; porque estaba ya en el la verdad. No se puede, pues, enseñar cobrando de oficio, más verdad que la que corresponde a las técnicas y destrezas; la orientación del comportamiento social, el discurso sobre la naturaleza, los interrogantes fundamentales del existir histórico y las prácticas que inician en la responsabilidad social, no admiten maestro, son don divino. Solamente se puede, en verdad, de oficio, ser maestro de taller. Esto se sige pensando. Julián de Ribera, arabista español, venía a decir que el que sabe hace y el que no sabe enseña. En cualquier caso parece que enseñar, lo que se dice enseñar, o era pretensión de sofistas (en el mal sentido de la palabra en el que lo empleaba Sócrates) o un subproducto de la actividad de producir conocimiento.

Enseñar, cuando lo que se comunica es el último hallazgo de la maś puntera investigación, puede parecer más exhibición que enseñanza. Organizar los saberes en disciplinas y fijarlos dispuestos para ensañanzas a hombres medios - para muchos- mientras menos, mejor. No es lo más corriente encontar hombres de ciencia que se tomen radicalmente en serio el sentido científico que tienen la divulgación y la docencia. Si se acepta la actividad pedagógica, como en el caso de Sócrates, deben incorporarse tal cantidad de misteriosos argumentos que más bien semeja oficio sacerdotal, que profesión con la que ganarse la vida.

No, los alumnos no están naturalmente en condiciones de aprenderlo 
todo, ni la llamada curiosidad natural del joven incluye sin resistencias los saberes escolares. Puede aceptarse la imagen socrática del partero, con la modificación de que, frecuentemente, los dolores del parto del conocimiento los padecen los profesores. Ocurre como si el sistema y órgano del conocimiento no estuviera en la disposición correcta. Lo que inicialmente se supuso idílico intercambio espiritual entre el profesor y el alumno, se torna brega molesta e improductiva. Recuérdese el vocabulario pedagógico sobre desbrozar, desasnar, pelear, luchar, pulir, apacentar,...

Pensar de manera exclusivamente socrática la función docente puede llevar rápidamente al desencantamiento. Puede llevar, incluso, a una peligrosa división del trabajo pedagógico: los productores de mitos hermosos y los que se ocupan desconcertados en el trabajo escolar irreconocible. Se impone, pues, introducir el principio de realidad por el que entender que la función docente es un servicio social en el que se ocupan y trabajan personas que para conseguir éxito en sus cometidos han de superar gran cantidad de resistencias. Parece más bien como si casi nada estuviera espontáneamente dispuesto para el banquete cultural. Sobre todo, cuando, por motivos razonables, se intenta que coman todos, aunque no por igual. El esfuerzo ansioso por conseguir rendimientos escolares, se puede convertir en fuente de tensión que aumenta los inconvenientes y desestructura la relación profesor alumno. En esta situación, siempre entra en conflicto la propia personalidad. En el acto pedagógico el Yo siempre está en juego.

\section{b) El mito ilustrado}

El otro movimiento cultural al que aludimos es la Ilustración, de la que todavía andamós entrando y saliendo. También allí se propuso un mito para explicar el nuevo cambio de perspectiva: el enorme viene al mundo como una tabla rasa y limpia en la que todo puede ser escrito. Es el mito de la omnipotencia pedagógica.

Cualquier apreciación pedagógica ha de partir -en contra de lo que estipula el mito ilustrado- del hecho de que la intervención técnica sobre el alumno arranca del estado real de la estructura cognitiva, perceptivo motórica y emocional. Se empieza siempre a trabajar sobre una tabla muy ocupada. la ventaja de este planteamiento es la de que desimplica personalmente en gran medida al profesor, creando una distancia protectora, producida por la objetivación científica de la situación didáctica. La distancia es un apoyo para el equilibramiento. Educar, enseñar, es una ocupación; la cual, como todas las demás, han de constituir en dato los elementos que configuran las situaciones. De lo contrario, como es frecuente, los hechos que no se conforman con los planes convierten a alumno y profesor en contrin- 
cantes de una magnífica pelotera. Unos optan por inhibirse y resolverla con las evaluaciones; otros se complican más y concluyen por plantear el dilema "o este alumno o yo".

El punto de vista ilustrado lo creemos adecuado, aunque era excesivamente prepotente. El espacio de escritura en la tabla se encuentra fuertemente condicionado. Precisamente, parte del margen de escritura depende del conocimiento de lo que ya se encuentra escrito. Dar por supuesto que con todos los alumnos, todo puede ser realizado y ello dependiendo de la iniciativa y dedicación del profesor, puede ser desestabilizante, por el nivel de tensión que puede producir.

En ambas modalidades de reconstrucción simbólica de la tarea docente se da una visión positiva y gratificante de la propia labor, se proponen motivos válidos de identificación con ella. La disgregación del "Yo profesional." - como gusta decir Ada Abraham- podría venir por la ansiedad, o el desencanto impotente. Pero, como decimos, en la superficie, hoy, se ha generalizado el lenguaje formalmente positivo acerca de la función. Por debajo, las aguas corren un poco turbias. Además de los componentes míticos positivos, también se respiran otros más negros y negativos.

\section{c) Mitos siniestros}

En todos los mitos, lo bello se encuentra muy próximo a lo siniestro. $\mathrm{El}$ mito siempre nos descubre, oculto en sus oropeles, un antropomorfismo, una lección sobre el hombre. el mito, a veces, también nos relata, sin pudor, los sentimientos infames y desmerecedores que el trabajo de maestro despierta o induce, cuando el coro que se canta no es el de las musas favorables, sino el de las musas esquivas.

Este es el caso de Ivan Bunin -Premio Nobel de literatura 1933- en su obra El Maestro1. Forma parte de un libro antológico que se abre con William Faulkner. Otro relato breve que nos muestra el extremo antinómonico también contenido en la percepción social. Turbin es un hombre en la flor del deseo, a los veintitrés años. Intentó ser militar de Academia y agrimensor, pero, nos dice el cronista, "tuvo que conformarse con hacer las oposiciones a maestro..." "La sensación que más frecuentemente le envolvía era de la soledad. Su amigo más comprensivo y frecuente era el pope del lugar".

Voy a extraer un párrafo que refleja en obscuro la tragedia de este otro héroe: "Soñaba en una vida desahogada, en tener buenas relaciones, en ser un hombre instruido, enterado de los progresos de la ciencia y de la políti-

1. Ivan Bunin, El maestro, Ed. Plaza y Janés S.A., Barcelona, 1966. 
ca. Pero estos sueños fracasaron. Soñaba con organizar la escuela de un modo ejemplar, en escribir artículos sobre pedagogía y en redactar manuales. Pero también estos sueños se fueron apagando día tra día... Después de muchas reflexiones decidió que lo más importante era completar su instrucción; después se buscaría relaciones que le ayudasen a ser un hombre". No se olvide que ya, para cuando habían surgido tales deseos de ser "nada menos que todo un hombre", ya era maestro.

La cara de Turbin no es como la de Duishen. Aquella cortaba el viento de vidas colosales. La de este otro maestro refleja un dolor en el que no cabe más remedio. j"Era como la de un muerto cansado, agotado, inexpresiva y con sello de sufrimiento’!...“¡¡Vaya con el pedagogo!...¡Pobre de él! ...Será, de seguro huérfano". La descripción y las exclamaciones proceden de un personaje secundario en la novela, más seguro de sí mismo y con ocupaciones de más rango social y beneficio económico.

Buena parte del profesorado que se inserta en el sistema de enseñanza, en los niveles básicos y medios, perdió las ilusiones de ser científico. Al propio tiempo, por la carencia, en ocasiones, de formación psicopedagógica fundamental y mecanismos sistemáticos de formación permanente en este carácter, se ven en la necesidad de responder a un conflicto docente con los recursos a partir de los cuales se encuentra mayormente seguro: los que refuerzan sus propios y peculiares rasgos de personalidad, aunque sea problèmática, y los que reproducen los modelos pedagógicos de comportamiento que mejor conoce; precisamente, los que ha padecido y criticado durante su personal época de alumno: los que representan tópicos culturales de las relaciones adulto-niño, profesor-alumno. La conducta del alumno adquiere, por este motivo, una condición reactivadora de todo lo que fue su propia historia escolar y familiar, posiblemente negadora o críticamente rechazada. Surge por aquí otro foco de ambivalencia que empuja a la desestabilización, o al abandono del interés inicial por la enseñanza.

Estos direfentes tratamientos del mismo tema, correlativos de aquellos otros planteamientos del discurso pedagógico que permiten plantear el asunto de las antinomias pedagógicas o de las contradicciones de la cultura y de la Pedagogía, son fidedigno testimonio de que, no sólo la existencia profesional de los docentes está socialmente cargada - que no saturada- de turbulencias, sino que en su personalidad hay acechando una voraz solitaria que se come el mito bello y aflora el esqueleto del mito siniestro. Estudiar y conocer las posibilidades reales de intervención que proporciona la competencia técnica y los límites técnicos de tal intervención es, a nuestro entender, un factor de personal equilibrio del docente. Cuando aquí empleamos la palabra técnica no queremos indicar que todos los problemas de la situación educativa se saldan con el conocimiento científico, que todos los problemas educacionales son consecuencia del desconocimiento pedagógi- 
co. Queremos indicar que la relación educativa no puede ser únicamente apasionada, que con sólo amor no basta. Muchos de los objetivos que persigue la docencia son proyectos culturales con efectos controlables, el control de los mismos en los límites que permiten las situaciones en fuente de seguridad.

\section{LA UTILIDAD DE LAS FICCIONES}

No es precisamente el discurso científico el más apto para conseguir el desvelamiento de tales percepciones sociales negativas, ni para cubrir emociones desencadenadas por juicios de valor contradictorios, ni para descarnar actitudes que camuflan y esconden juicios hirientes y crueles, sentimientos estúpidos y comportamientos marginadores. Ciertamente, las apariencias muestran el quehacer dedagógico como el más noble de los oficios y la más hermosa de las ocupaciones; eso afirma el lenguaje público. Pero, cuando por motivos de estudio científico se acerca la percepción a la representación conceptual, empleando instrumentos distintos a los libros de oficio, se descubre un núcleo reducido y turbio que puede tornarse en causa de malestar para personas predispuestas.

La zona del lenguaje en la que mejor se muestran estos placeres de imágenes es la literatura. Aquella zona de la expresión en la que el concepto surge sin la mordaza de la lógica y donde la imagen y la emoción intervienen como las otras leyes y explicaciones del pensamiento. El indicio que puede mostrarse en obras de creación literaria no lo puede olvidar aquellos científicos que estudian las relaciones entre comportamiento docente y microestructuras sociales, mecanismos de identificación, autopercepciones, actitudes de resistencia, migración ocupacional...estabilidad y equilibrio personal.

No se olvide que muchos hombres ilustres, a los que la sociedad aceptó que escribieran sus memorias, en ellas encontraron un hueco para criticar una escuela, dejar en ridículo a un maestro anónimo. Pareciera como si el terreno mejor abonado para el trabajo de un maestro fuera la zona y el estrato de la mediocridad. La Summa y tratado de estos pensamientos a hurtadillas sobre la función docente alguna vez debiera ser escrita. Lo que no debe esperar mucho es el análisis crítico de estas condensaciones literarias y coloquiales que muestran, por asociación semideliberada otros planteamientos más conscientes y centrales en una narración, la estructura profunda de una apreciación sociocultural. Nos invitaría a despertar a ratos del mito, en el que conviene ciertamente, también a ratos, dormir.

Antonio Gala, escritor español muy conocido, en una delicada obra teatral, entre otros asuntos, saca a relucir los conflictos culturales y la insosla- 
yable necesidad de que cada generación arriesgue su forma de libertad. La obra se titula El cementerio de los pájaros.

En el desenlace del drama hay un disparo que mata a la juventud. Mientras el espectáculo está abrumado por el rigor de la tragedia, queda perdido un pormenor, casi una mera mueca de la larga escena: la que apretó el gatillo fue una maestra asturiana, de la región norteña de España

Yo creo que en el ámbito del mito y la creación literaria hay un filón poco explotado en el que encontraríamos, de seguro, elementos valiosísimos par la reconstrucción sociocultural de las representaciones activas e influyentes sobre la educación. En las descripciones más solemnes de los libros especializados se plantean versiones pedagógicas en las que siguen convertibles los universales griegos: la belleza, la bondad, la verdad, la unidad... En tanto que en esta literatura, por aquí y por allí, se hacen otras cuentas, la verdad no se busca por ser bellas, sino por sus utilidades. Y la belleza que es acariciada y cultivada, no es la que se ensalza como canon de verdad; este canon se lo guisan los científicos que, según dicen, se ocupaban de otras cosas. Las gentes mandamos a los niños a los colegios, pero en las grandes epopeyas no es precisamente un héroe el maestro. Esta lección hay que estudiarla, como medicina para alcanzar el principio de realidad que equilibre nuestra personalidad un poco tendida sobre la mitología.

Catherine Clérnent, no se si lo recibe de alguién, utiliza el término "Bildungue Roman". Bildungue es la forma "zazifié" de Bildung (formación): la ficción de un aprendizaje. Este género novelistico - como tal se proponeha sido estudiado como trayecto de la vida de un héroe desde su infancia inconsciente hasta la edad madura y consciente de si misma.

Los ejemplos propuestos por ella, como prototipicos, son Wilhem Meister de Goethe, Simplicius Simplicissimus de Grimmelshausen, Henri le vert de Gottfried Kellers. Y, puestos en la pista, muchos otros que pedagogicamente pasaron descuidados. Un caso, podría tal vez ser Médecin de Campagne de Balzac. Un caso peculiar del género, porque el verdadero viaje no lo hace una persona sino todo un pueblo. Situado en el valle que dominan los picos de Saboya y del Delfinado, es educado y — nótese que el guía que orienta la colectividad no es un profesor cualquiera, sino un médico-. El punto de arranque, el estado inicial en la historia de este pueblo es el de las ideas y proyectos que inspira una miseria laboriosa, con personajes que creían a Medea una Archiduquesa de conducta equívoca. En tal heróica labor de crianza de un país, se producen incidentes menores por los que disponer la existencia de una escuela primaria gratuita.

El héroe -que no hace en todo el relato más que consignar la peripecia pedagógica - cuenta: "Para desempeñar esta importante función (la de instructor o maestro) escogí a un pobre sacerdote sarmentoso, rechazado por toda la provincia y que ha encontrado entre nosotros un asilo para su vejez. 
La maestra de escuela es una digna señora arruinada que no tenía donde establecerse..."

Todavía en muchas películas modernas se reviste al pedagogo o maestro -como decía un colega en una sesión académica solemne- con los rasgos que Valle Inclán advierte en el Marqués de Bradomín: feo, católico y sentimental. Casi parece, en ocasiones, un ensañamiento con la figura del maestro, del que en el momento místico se tomó el hombre y la función para identificar al Dios encarnado de los evangelios.

Cuando el historiador nos arguyera que el ambiente histórico descrito en muchas ficciones es antiguo y superado, para nosotros debe suponer, muchas veces, una simple coartada.

En mi opinión, en cambió, la defensa de la imagen del profesor, en nuestros ambientes culturales, han de emplear, al menos transitoriamente, el mecanismo social más extendido: la mayor profesionalización de los docentes. Conlleva un aumento del conocimiento en y de la actividad, y un acercamiento del protagonista docente a la trama de focos de decisión del sistema social que podrían lógicamente corresponder.

Cuando la ilustración inventa la escuela moderna y el sistema de enseñanza, las luces y las disciplinas, se produce un quia pro quo, un cambio de perspectiva. La trama histórico social, la llamada educación informal, la que estaba entremetida en la voz crianza, se oculta en beneficio del que se considera ahora el descubrimiento supremo: no sólo el hombre es plásti$\mathrm{co}$, sino que tiene por artífice otro hombre. La escuela es el taller social, los hombres se hacen en las escuelas. Unos seguirán diciendo que se hacen, otros cambiarán a que se deshacen, pero todos señalarán con el dedo a esta escuela que se propone como fragua de la humanidad. Distribuir equitativamente las oportunidades escolares en el capitulo más peleado de la justicia social. Después de comprobar el desarrollo institucional de la ensañanza y las condiciones históricas y sociales necesarias para que tal desarrollo se produzca, hablar de sociedad desescolarizada no es más que un componente a introducir en el discurso, para evitar la absolutización de la misma, o una frivolidad.

La escuela, como institución, es el cuerpo social de una idea, estudiar todos los matices del proyecto - los sublimados y los reprimidos-es una imperiosa necesidad. La escuela en tanto ocupación es una tarea social que entra en el reparto del mercado de trabajo. La sanción y representación social de tal menester es un indicio insoslayable -aunque no el único-para entender el comportamiento de la persona , cuya fatiga en ella tiene el origen.

En la velocidad vertiginosa que ha adquirido el dinamismo social, los hombres se agarran a una tabla que sigue flotando e hinchándose: la escuela; Lo que muchas veces olvidamos es que lo que realmente cogemos son las mangas de un maestro. Este discurso, un tanto crispado sobre la enseñanza 
explica, en parte, el ocultamiento de la identidad profesional de quien se dice químico, aunque es profesor, de quien dice filólogo y no profesor de filología....Don indicios.

\section{EL CONOCIMIENTO PEDAGÓGICO Y LA ECOLOGÍA DEL AULA}

Los anteriores testimonios no han sido presentados porque agoten en rasgos toda la variedad de ambigüedades que aparecen en la estructura profunda de la percepción y de la expresión social de la función docente. $\mathrm{Ni}$ están todos los matices ni aparecen todas las variantes respecto del espacio y el del tiempo. Pero si queda clara la ambivalencia radical con la que se interpreta la función. De un lado, por lo tanto, estimula la identificación y la afirmación personal, en tanto que actor docente, movilizando la actividad en la dirección de aumentar la corriente de gratificaciones de todo orden -intelectuales, afecticas, de posición y poder social-, de otro, favorece la situación de extrañamiento personal, en tanto que actor en este drama, frenando el dinamismo de la actividad, con lo que se reduce el potencial de gratificación personal y la valencia del enalce entre el individuo y sus cometidos sociales, reforzando la alienación.

Tal circunstancia de ambiguedad, que puede focalizarse en cualquiera de las posiciones extremas (idealizar o desrealizar la función) tiene tanta importancia, desde el punto de vista psicopedagógico, cuanto al tomar posición en el sistema personal de comportamiento, convierte multitud de estímulos generalmente irrelevantes o inespecíficos en funcionalmente relevantes. El sujeto se hace sensible a una gama cada vez más amplia de estímulos reforzando la identificación o disociación entre la persona y la función. La tendencía espontánea será, por principio, la de aumentar el ámbito de comportamiento por el que radicalizar la vertiente adaptativa (identificación) y la positivización expresiva; o a la inversa. En el lenguaje coloquial las expresiones son claras: "cada vez me gusta menos", "cada vez me muevo y locomociono por los niveles mínimos de implicación"; o bien, "cada vez le encuentro más interés y atractivo".

Pero, la ambigüedad no se reduce a la bipolaridad del autoconcepto que sobre la función racionalice la persona o se simbolice socioculturalmente.

Hay aspectos de la ambivalencia que solamente empiezan a morder internamente con la función, subsumida intelectualmente en su problemática y situada cardinalmente en el foco de la dialéctica cultural en torno a los problemas de la educación. Es entonces, cuando se advierte que el catálogo de fines, metas, cometidos, que verbalmente se adjudican en el discurso educativo general al sistema de enseñanza y al conjunto de roles docentes, recorre las cornisas más elevadas y las más bajas de los proyectos concebibles 
sobre el hombre. La Ilustración acertadamente hizo incompatible la introducción de la racionalidad en el ámbito de las ciencias humanas y la presencia mitológica de acciones ultradeterminadas predestinadas. Acertó a identificar al hombre y sus sistemas de interacción, o con los que interacciona, como fuentes de explicaciones del comportamiento. Pero se equivocó al suponer que ello significaba la posibilidad de fabricar los hombres en los talleres de la escuela. No identificó con precisión a los agentes y las modalidades de intervención sobre el comportamiento del individuo.

Estas exageraciones fueron las que ridiculizó Miguel de Unamuno en aquél proyecto de hacer hombres "more pedagógico", cuyo proceso habría de iniciarse casándose deductivamente.

Cuando el profesor atiende a la totalidad de los alumnos y alternativamente mueve la cabeza desde las tablas de finalidades al intervalo de posibilidades dentro del espacio físico, social y cultural de su clase y disciplina, no puede, sino confirmar y confirmarse en que el ámbito de la escuela es el área de lo imposible. En forma ya hiriente, y con una micra de prepotencia, el sociólogo o el filósofo corroboran el asunto con el dictamen para la Pedagogía de "ciencia imposible". Definitivamente queda abandonado el docente a la ambivalencia original y sin poder salir por la puerta de la dialéctica racional, sino más que por la del arte, la intuición, la propia iniciativa...Señores: parece exigirse a estos hombres que sean islas.

De otro lado, todo maestro es un testimonio viviente de una teoría voluntarista de la acción. Es decir, que en el proceso de desarrollo humano, en la larga secuencia o procesos de cambios de estado del complejo sistema de conductas que compone la personalidad, hay un margen real de intervención subjetiva, supone que se pueden producir cambios que no derivan del movimiento activo de la historia, la circunstancia o el sistema social; rigurosamente se testimonia que quedan márgenes de intervención subjetiva, de procesos que pueden ser desencadenados a partir de objetivos plausibles con la naturaleza del sujeto (respeten leyes de su funcionamiento neuropsicológico) y pausibles culturalmente (respeten las normas generales vigentes culturalmente),

Tales márgenes de intervención subjetivo deben apreciarlos el profesor, en virtud del estudio concienzudo de los procesos que pueden tener lugar dentro del ámbito escolar. Ya sabemos que evolucionan dentro de un intervalo muy variable y altamente condicionado por la tipología de la locomoción que la personalidad promueve (o en ella se induce) dentro del campo de fuerzas extraescolares. El sentimiento límite de impotencia, puede generar en el profesor desestructuración de la acción pedagógica posible aumentando la disfuncionalidad de su intervención en el aula.

La disfuncionalidad del comportamiento puede interpretarse como carencia de idoneidad para la función. Tal es una de las pendientes del males- 
tar interior. Promover, pues, la competencia sobre la tarea docente, o la ampliación de las alternativas de acción posible en función de la modificación cualitativa de las circunstancias, tienen todos los indicios de convertirse en mecanismo perventivo para el malestar psíquico. Y, a la inversa, dada la inadecuación entre la amplitud de las adjudicaciones que se cargan al rol docene y la incapacidad instrumental de satifacerse dentro del sistema escolar, la incompetencia pedagógica, en determinadas circunstancias, o coincidencias comportamentales del individuo, puede alimentar el malestar.

La acción pedagógica debe recuperar la calidad estética contenida en los mitos, pero por el aporte de objetividad y racionalidad posible. En el mito estaba protocientíficamente planteada la pregunta que sigue escociendo a las Ciencias de la Educación: ¿Qué y a quien enseñar, con qué mediaciones?

Esta pregunta, que señala con el dedo a la intervención pedagógica, contiene en su interior materia de indagación como para satisfacer la más exigente de las curiosidades intelectuales. Quien entra en la escuela de párbulos o de universitarios, no inicia una actividad cuyo significado se agote en el cumplimiento de una obligación administrativa. Dentro de las circunstancias del aula puede recuperarse la ilusión de ser científico. Con una particularidad que no revisten otras formas de tecnología. Si algunos han de hacer una casa o una herramienta han de someterse a las necesidades o de la situación, por más que el margen de subjetividad aplicable al caso sea grande. En el caso de la intervención pedagógica, el proceso cognitivo puede desarrollarse satisfactoriamente controlado, a un tiempo, la necesidad cognitiva del alumno y la del profesor, porque el aula se puede transformar en laboratorio. El profesor puede, sin alteración de la secuencia específica de aprendizaje, acomodar el diseño a sus especiales dotes o habilidades. he comprobado la mejora general del clima del aula, con mejora de los niveles de rendimiento - como por efecto de simpatía - en áreas cognitivamente distantes- cuando el profesor contagiaba a los alumnos con su afición por la ornitología. He asistido al galardón de una obra de un docente de enseñanza media en la que su investigación se dirigía con éxito a construir un diseño de aprendizaje en el área de las ciencias naturales. Partiendo del estudio sistemático de un ecosistema en el que se encontraba científicamente interesado. En el mismo acto se premiaba a un matemático que planteaba una investigación sobre la naturaleza y estrategias de recuperación en la quiebra del aprendizaje escolar de las fracciones, señalando una reducción de fracasos del 95 por ciento.

Personalmente he superado con facilidad la actitud amenazante de grupos universitarios, para sesiones de enseñanza especialmente problemática, objetivando la situación en general y en sus particularidades, como casos concretos y figuras de comportamiento grupal especialmente atractivas desde el punto de vista técnico pedagógico. 
Queda claro lo propuesto. Pero, no nos engañemos. Cumplirlo exige que se superen formas arcaicas de organización de la institución educativa y del sistema de enseñanza. Cuando uno oye hablar a muchos profesores, parece como si la unidad básica de enseñanza se compusiera de profesor y de alumno; su representación matemática fuese la de la ecuación lineal; el tipo de causalidad apetecible la neutoniana de la acción-reacción equivalente. Estos son los personajes del mito bello y del siniestro. La unidad de intervención pedagógica debe diluirse en equipos docentes de mutuamente se complementan y soportan, en grupos de profesores que en equipo investiga y complementan su actividad. Lo que llamamos libertad y autonomía sagrada de cátedra puede ser la tumba psicológica de los más débiles, o la consagración de la prepotencia y de la inconsistencia de la intervención en los que se crecen más seguros.

Aún recuerdo con enorme alegría intelectual las consideraciones de anteriores reuniones científicas sobre el tema, cuando la profesora Lucille $\mathrm{He}$ raud me comentaba: si ya tenemos ante nosotros un profesor estresado o bajo la pesada losa de la neurosis, la primera acción debe dirigirse hacia la reconciliación del paciente con su propia actividad pedagógica.

Evidentemente está en contradicción flagrante con estas estimaciones, que he presentado, la actitud de muchos científicos españoles y de otros paises que rechazan en sus Departamentos universitarios investigaciones para optar al grado de doctor en una especialidad determinada y que llevan por asunto un problema didáctico de la especialidad. Lo que nosotros intentamos salvar, ellos lo condenan.

Lo que he querido decirles, en palabras sencillas se puede resumir diciendo: hay especialidades científicas o tecnológicas en la actualidad que tienen por parientes en la antigüedad a los barberos; también los profesores pueden, en todos los niveles de enseñanza redescubrir las calidades de su acción. Este redescubrimiento, como el de la hierba buena, es el buen remedio para algunos padecimientos. 